\title{
Epistemological Base of Rural Secondary School Science Teachers: A Case of Rakai District in Uganda
}

\author{
Disan Kutesa \\ Department of Foundations of Education, Kyambogo University
}

\begin{abstract}
The study was an investigation of the Epistemological Base of Rural Secondary Science Teachers in Uganda, a case of Rakai district. Epistemology enquires into the possibility, nature, origin, scope, validity, and limits of human knowledge. The problem of the study was poor performance of students in sciences in the rural secondary schools in Ugandan Certificate Examinations (LJCE). The central point was to find out the philosophical beliefs of the rural secondary science teachers about how the educators come to know anything. A non-experimental research design was employed in the study. The research was carried out in ten selected schools using purposive sampling technique. Regarding data collection, the researcher administered fifty (50) questionnaires to fifty (50) teachers; interviewed ten teachers and carried out classroom observations of ten live lessons. The findings of the study revealed that teacher's conceptions about mode of knowing falls under three sources of knowledge namely, Authority, here knowledge is acquired through consulting experts in their fields, Sense-perceptual experience, this involves usage of empirical instruments and Reason, where the logical process is employed to acquire knowledge. The conclusion was that beliefs about source of knowledge have significant bearing on the methods of teaching. Many rural science teachers employ teacher centered method of teaching. It was clear that teachers assume that learners do not have knowledge; hence the Bucket theory of mind is central in their teaching learning process. Many teachers appeared to do things the way they w re taught, in other wards a number of rural science teachers tended to be doing activities whose underlying assumptions they were not clear of. A functional approach to the teaching of Philosophy in Educational programs is recommended.
\end{abstract}

Keywords: Epistemology, science, teaching.

DOI: $10.7176 / \mathrm{JEP} / 11-19-02$

Publication date:July $31^{\text {st }} 2020$

\section{INTRODUCTION}

Considerations concerning the source of knowledge, which include philosophically divergent instruments of knowledge, Sense perceptual experience, Authority, Reason, Intuition, and Revelation, have a significant bearing on educational issues and practice. However, it is doubtful whether secondary school teachers are conscious about modes of knowing in their choice of teaching/learning methods.

It should clearly be stated that knowledge and truth may carry different meanings in that knowledge is the apprehension of reality, or the awareness and understanding of particular aspects of reality (Lemos, 2007). However, from classical accounts, for anyone to lay claim to knowledge, such claims must be true and believed with justifications. Hence, Knowledge is sometimes defined as justified true belief, because to know something, one must believe in it, one's belief must be true and one's reason for believing it must be satisfactory in the light of some standard (Ayer, 1956) Thus, S' knows that P', If and only if:

1) $P$ is true (For $P$ to be true, it must be independently verified by an independent researcher)

2) $\mathrm{S}$ is sure that $\mathrm{P}$ is true

3) $\mathrm{S}$ has the right to be sure that $\mathrm{P}$ is true

On the other hand, truth is the correspondence between concepts and reality; between the statements made about a particular reality and that reality spoken about. In this study, knowledge refers to truths at all levels. There is need for secondary school teachers in rural areas to have clear conceptions about how knowledge is acquired in order for teaching/learning methods to be selected intelligently. In schools, students learn various forms of knowledge, skills and attitudes which call for a variety of methods. Such methods need to be consciously determined and an epistemological orientation is essential in this regard.

\section{Need for epistemological orientation}

It is important for the secondary school teachers in rural areas to be aware of the ways of knowing because this will help them in selecting what materials to teach, what teaching methods to use and where to place their emphasis during the teaching/learning processes. Maloba (1991) observed that teachers are central factors in the education of the child. Teachers are required to have a thorough understanding of methods of how students acquire knowledge, their personal care, upbringing, discipline, and active participation in the academic and co-curricular programme in the school.

This study sought to disclose rural science secondary School teachers' conceptions about the source of knowledge in Rakai District. This was considered important because of the poor performance of students in 
certification of examinations. It was assumed that aching/learning methods employed by rural science teachers were reflection of their beliefs concerning the source of truth. Defords (1985: 35) holds.

"Different ways of teaching and learning are not merely temperamental variations in regional outlooks but at the bottom there are ideological differences people hold."

This prompts a question of whether many rural secondary school Science teachers do actually have clear conceptions of methods of knowing. The other question is, if they do, to what extent do these conceptions influence their choice of teaching/learning methods?

There is the need to find out rural science secondary school teachers' conceptions about the method of knowing. According to Akinpelu (1981), it is in the area of epistemology that the relevance for education and especially for the classroom teaching and learning is the most noticeable. Henceforth, the search for truth and knowledge is the common task of both education and philosophy.

For a person to be called educated, he/she must not only possess specialized skills, but he certainly also possesses a considerable body of knowledge together with understanding (Akinpelu, 1981). This prompted the researcher to find out the source of reliable and dependable knowledge among rural secondary school teachers. Hab'imana (2001) argues that teachers to be effective, they should be aware of "ways of knowing" in their particular subject. This will keep them in selecting what materials to teach and where to put emphasis in their teaching of those subjects.

Nakibirige (1999) found out that teachers in Uganda were using teaching methods without Philosophical beliefs; many were doing things according to the way they were taught or by intuition. So, since according to Nakibirige (1999), many teachers were not aware of the proper teaching methods, there was likelihood that rural secondary teachers are not aware of the generalized sources of knowledge. So Nakibirige's revelation further prompted the researcher find out whether teachers in rural secondary schools are aware of the generalized sources of knowledge because educational enterprise to be fruitful, the teacher must be aware of the generalized methods of knowing.

\section{Instruments of knowledge}

To know is one of the most fundamental urges of man. Man always wants to know the truth about his surroundings as well as the truth about himself. Otherwise, all his knowing would not only be futile and senseless but also harmful and disastrous if it was not knowing the truth to guide him in all his actions. The ultimate aim of this search for truth is to know not only a truth or truths but the truth purely and simply, implying reliable and valid knowledge. So this called for a need to research on the generalized and right modes of knowing. John Dewey asserted that the search for truth and knowledge is the common task of both education and philosophy. Teachers transmit various types of knowledge according to their disciplines. Thus, it is appropriate for a teacher to know the generalized sources of knowledge: how we know. Do we know through Sense- perception experience, Authority, Reason, Intuition, or Revelation?

Source of knowledge refers to instruments of knowledge or modes of knowing, or ways through which knowledge is acquired. Philosophically there are different sources and theories of knowledge. These include:

\section{Instrument of knowledge}

Sense-perceptual experience

Authority

Reason

Intuition

Revelation

\author{
Theory of knowledge \\ Empiricism \\ Authoritarianism \\ Rationalism \\ Intuitionism \\ Revelationism
}

Sense-Perceptual experience is one of the modes of knowing. Its theory is called Empiricism and it is confirmed by the evidence of senses, thus seeing, hearing, smelling, tasting and feeling. Authority is another source, according to the proponents of this source, a great amount of our knowledge is derived from the testimony of some authorities like text books, pamphlets, and teachers, among others. Reason is also a method of knowing and the adherents are called rationalists for them, knowledge is gained through reason or logical process unaccompanied by observation of actual state of affairs. On other hand, "tuition refers to a subconscious process in a person who intuits in a field in which he is well experienced, the proponents are known as intuitionist. The last source of knowledge is revelation. According to this source, revealed knowledge is disclosed to man from God. God is the father of all knowledge so to get reliable knowledge; we need to refer to the Bible, Koran or religious men and women.

The problem of the study lies in inadequacy of awareness of rural science secondary school teachers' philosophical beliefs about the source of knowledge and their bearing on educational practice. Are rural secondary teachers for science aware of the generalized sources of knowledge? And if they do, which source is the most dominant? The other question is, is there a relationship between source of knowledge and teaching learning methods? 


\section{Statement of the problem}

Different educational philosophies and educationists place varying emphasis on these general sources of knowledge: Sense-perceptual experience, Authority, Reason, Intuition, and Revelation.

Many authors had shown indirectly that teachers are not well versed with sources of knowledge; like Nakibirige (1999) wrote that teachers are not well versed with good teaching methods, yet there is a relationship between teaching methods and sources of knowledge, so there was a likelihood that students in rural secondary schools perform poorly because their teachers are not aware of the right sources of knowledge.

The problem of the study lay in inadequacy of awareness of the commonly accepted modes of knowing among science teachers in rural secondary schools and establishing which one predominantly underlies their teaching strategies.

\section{Purpose}

The purpose of the study is establish the structure of Philosophical beliefs among rural secondary science teachers about the source of knowledge in order to indicate its practical bearing on what goes on in the school with regard to teaching/learning methods.

\section{Objective}

This study intends to establish rural science secondary school teachers' conceptions about the source of knowledge during teaching learning process.

\section{Scope}

The scope includes mainly an epistemological investigation of rural secondary teachers' conception about the issue of knowing in Uganda, with specific reference to schools in Rakai District. Also the choice of this district aimed at minimizing the costs of the project since schools under the study were close together, within reasonable proximity of the researcher.

Using inductive methodology, it is projected that information gathered from teachers in Rakai District is a representation of all rural teachers' conceptions about issue of knowing in Uganda.

Only ten schools were considered. Concerning content, the study was limited to the epistemological base of rural secondary teachers in Uganda. It also undertook to determine whether secondary school teachers' conceptions have an influence on their general teaching methods in the educational situation.

\section{Significance of the study}

The study was expected to disclose rural secondary school teachers' conceptions about the source of knowledge in the context of the classroom. Understanding how science teachers' conceptions about the instruments of knowledge fundamentally influence the choice of teaching/learning methods is essential to educational practitioners. The findings of this study are therefore deemed to be of importance mainly in three ways:

(a) Helping educationists and" educational leaders in their assessment of teachers' practices by throwing fresh light on the means of transmission of knowledge in schools.

(b) Motivating secondary science teachers in service to reflect on the kind of fundamental beliefs they hold about the alternative teaching methods.

(c) Helping to stimulate new thinking about approaches regarding educating and training of secondary teachers in teacher education programme.

\section{Source of knowledge}

Table I presents rural secondary teacher's beliefs about the source of knowledge. From Table 1, a big number agreed with Authority as the most reliable source of knowledge $(74 \%)$ on the other hand, there were a moderate number of teachers who respectively agreed

Table 1. Teachers' conceptions about the source knowledge.

\begin{tabular}{lll}
\hline Source of knowledge & Response & Teacher \\
\hline Authority & Agreement & $74 \%$ \\
Intuition & Agreement & None \\
Revelation & Agreement & None \\
Sense-perceptual experience & Agreement & $22 \%$ \\
Reason & Agreement & $4 \%$ \\
Total & & $100 \%$ \\
\hline
\end{tabular}

With sense perceptual experience (22\%) and reason (4\%) 


\section{DISCUSSION AND INTREPRETATION OF RESULTS \\ Introduction}

This is the outcome of the Discussion that determined the conclusions, which led to recommendations.

\section{Research question}

This research question aimed at establishing secondary science teachers' conceptions about source of knowledge. It stated: What is the epistemological base for rural science secondary teachers in Uganda? The findings of the study revealed that the predominant source of knowledge was Authority (74\%) followed by Sense perceptual experience $(22 \%)$ and Reason $(04 \%)$.

The findings can be attributed to the fact that all various sources of knowledge have something to offer to teachers. Consequently, rural secondary teachers do not conform to one specific source. More to that it was hinted on in literature review that each source has definite areas of weakness as well as areas of strength from the educational process stand point.

However as seen above, for many rural secondary teachers for science, Authoritative source is very pronounced yet they are supposed to dispense scientific knowledge, yet true and dependable knowledge is one got from five senses that is feeling, seeing, hearing and smelling. Truly, there is need to use teaching aid and practical's in teaching all practical subjects. Referring to Akinpelu (1981), he observed that no school of thought can be regarded as sufficient to supply all a teacher needs to make him a successful professional. So an educator may have to adopt ideas from a number of them in an eclectic fashion, likewise an effective teacher needs to be aware of all sources of knowledge and employ or consult sources of knowledge depending on the subject. Field findings showed that rural secondary teachers aimed at pouring contents in the mind of the learner-(jug mug theory).

In summary, it may be said that whichever choice a teacher makes, is alright as long as one is fully convinced of the justification for his decision. In principle, this condition allows teachers to plan learning experiences within the context of what they believe to be reliable source of knowledge. Scheffler (1973:85) further supports the view when he says:

“......If a justification is needed for a teachers' scholarly and theoretical sophications regarding his work, it is not that, lacking it he cannot manage to teach, but having it, the quality of his effort and role is likely to be enhanced".

\section{CONCLUSIONS}

From the foregoing findings of the study, the conclusion is twofold, firstly, it was concluded that rural secondary science school teachers beliefs are eclectic in nature. This means that there is no distinctive source of knowledge under which rural secondary teachers' beliefs fell but mostly they put more emphasis on Authoritative source. Secondly the findings also indicate that most of the reasons for the choice of teaching method are not generally based on philosophical beliefs. Many teachers appeared to be doing things according to the way they were taught or by intuition. In other words, a number of teachers tended to be doing activities whose underlying assumptions they were not clearly aware of, and clearly explains why many of their students perform poorly in Uganda Certificate of Education.

For effective teaching, teachers irrespective of the financial stand of the school, need to be creative, innovative and assiduous if they are to realize academic excellence. Authority as a dominant source found in the field, should be discouraged especially for all Sciences.

\section{RECOMMENDATIONS}

From the foregoing findings, discussions and conclusions, the researcher made four recommendations:

The first recommendation is that: Teacher Education Programme should incorporate topics concerning philosophical beliefs and their role in the educational process. Also workshops should be organized for all secondary school teachers, aimed at orienting them on the utmost need of having clear conceptions about source of knowledge. Teachers need to know the limitations of different sources of knowledge so as to give dependable knowledge all the time in educational situation. This is due to the fact that all sources of knowledge have limitations of which, according to the research carried out, many teachers are unaware of and may end up giving unreliable knowledge i.e. "poison" to their students. This would help to ensure that teachers have clear conceptions about the source of knowledge as well as ensuring that philosophical beliefs play their expected role in guiding teachers' activities in the school. These workshops, conferences and symposiums should also e extended to tutors and lecturers of Philosophy of education so as to meet and share their knowledge, experience and lessons learnt. This would go a long way to help in devising means of how best they can improve the teaching of Philosophical beliefs in colleges and universities.

The second recommendation is to sensitize policy makers, educational planners and teacher educators about the role of Philosophical conceptions in the educational process. Lecturers and tutors of Philosophy should be facilitated so as to publish books simplifying Philosophy of education. The unit of Philosophy of Education in 
Teacher colleges and Universities should be given more time as far as teaching is concerned so as to give enough "doze" of Philosophy to teachers during pre-service.

The third recommendation is that both in-service and pre-service teachers in secondary schools should be made aware, that there is a relationship between teaching methods and sources of knowledge, and the philosophical reasoning should be given to them. This should be done through organizing refresher courses, seminars, tutorials for pre-service teachers, among others.

The fourth recommendation is to make it clear to secondary school teachers that during teaching-learning process students should be fully involved so as to develop their reasoning capability, the teacher acts as an awakener, always intercommunication should be emphasized for pupils to exhibit their native intelligence and develop their reasoning faculties, the knowledge they will get will be part of them forever.

\section{REFERENCES}

Akinpelu, J. (1981). An Introduction to Philosophy of Education. London: McMillan Publishers.

Anderson, L. M. (1989). Research in classroom, the study of Teaching and Instruction. Oxford: Pergamon Press. Ayer. A.J (1956) The Problem of Knowledge Penguin books

Battista, M. (1985). Philosophical Anthropology. St Peters Pontifical seminary, India.

Butler, J. A. (1966). Educational Philosophies for Teachers. Columbus: Ohio Merrill.

Defords. D (1985) Validating the construct of theoretical orientation in reading instruction. Quarterly .20

Farrant. M. A. (1983). Principles and Practices of Education. Singapore. Longman Group Ltd.

Hab'lmana. J. 8. (2001). Philosophy of Education. Nkozi NTC.

Kneller, G. E. (1971). Introduction to Philosophy of Education. New York: John Wiley and Sons.

Lemos N (2007). An introduction to the Theory of Knowledge. Cambridge University Press

Maloba .S (1991) Education board of Governors rules and operational guidelines.MEO circular letter No ME 212718

Nakibirige M (1999). Primary and Secondary Teachers conceptions about the nature of the Educand in Kampala Schools .MED Dissertation of MUK

Norton, B (2000) Identity and Language learning: Gender, Ethnicity and Education Change. Harlow: Pearson Education

Peters. R. S. (1973) Philosophy of Education. Oxford University Press, New York.

Sartre, J. P. (1957) Existentialism and Human Emotions. New York Wisdom Library.

Scheffler.l (1993) Reason and Teaching. Routledge and Kegan Paul. London 